\title{
Compressive behavior of steel fiber reinforced- recycled coarse aggregate concrete with equivalent compressive strength
}

\author{
Danying Gao ${ }^{\mathrm{a}, \mathrm{b}}$, Lijuan Zhang ${ }^{\mathrm{a}, \mathrm{c}, *}$, Michelle Nokken $^{\mathrm{c}}$ \\ ${ }^{a}$ Research Center of New Style Building \& Structure, Zhengzhou University,No.100, Daxue Road, Zhengzhou, \\ Henan, China, 450001 \\ ${ }^{b}$ Henan University of Engineering, No.1, Xianghe Road, Zhengzhou, Henan, China, 451191 \\ ${ }^{c}$ Faculty of Engineering and Computer Science, Concordia University, 1455 de Maisonneuve West, Montreal, \\ Quebec, H3G1M8
}

\begin{abstract}
Experiments were carried out on over 100 specimens to characterize the compressive behavior of steel fiber reinforced-recycled coarse aggregate concrete (SFRCAC). Emphasis was placed on the combined effect of steel fibers (SFs) and recycled coarse aggregate (RCA) on the axial compressive behavior of SFRCAC with equivalent compressive strength. Test results indicate that with the addition of SFs, Young's modulus and stress-strain curves of SFRCAC are similar with natural coarse aggregate (NCA) concrete, but the critical strain has significant increase with increase of SFs content and RCA replacement ratio. Regression formula of compressive strength, Young's modulus, critical strain and constitutive model of SFRCAC were proposed.
\end{abstract}

Keywords: Recycled coarse aggregate; Steel fibers; Compressive strength; Critical strain; Stress-strain curve

\section{Introduction}

Recycling construction and demolition waste were initiated during the Second World War due to the difficulty of acquiring natural materials. Since then, extensive research

${ }^{*}$ Corresponding author, Tel: +8613653838353

E-mail address: gdy@zzu.edu.cn( D. Gao), floycn526@163.com (L. Zhang), m.nokken@ concordia.ca (M.Nokken) 
has been conducted worldwide to develop the production of recycled materials, promoting sustainable methods of construction. One of the most effective approaches is to use waste concrete from construction and demolition as coarse aggregate in fresh concrete. Available studies have proved that the recycled coarse aggregate concrete (RCAC) is a potential solution to minimize the consumption of natural aggregate resources [1-6]. However, so far RCAC has been only permitted for use in non-structural applications such as roadway base since it is regarded as inferior to natural coarse aggregate concrete (NCAC) in terms of its structural properties. Available studies have illustrated that recycled coarse aggregate (RCA) has higher porosity and water absorption than natural coarse aggregate (NCA), so compared to NCAC with same mixture proportion the compressive strength and Young's modulus of RCAC may decrease 20-25\%, critical strain may increase $10-20 \%$ [7-11].

Before RCAC is used in structural members, it must be ensured that the RCAC has satisfactory mechanical properties in comparison with NCAC. Steel fibers (SFs) have been recognized as reinforcing materials that could significantly improve the mechanical performance of concrete structural components [12-15]. Recently many studies have focused on steel-fiber reinforced recycled coarse aggregate concrete (SFRCAC). Previous research has shown that: (i) SFs could both increase the mechanical strength and modify the fracture process and toughness of RCAC, the behavior of the SFRCAC under compression becomes similar to that of steel fiber reinforced natural coarse aggregate concrete (SFNCAC) [16]; (ii) SFs can prevent and reduce the development of inherent micro-defects in RCAC [17]; and (iii) cost savings 
are significant for an optimum combination of RCAC and SFs due to quantified environmental benefits of recycled aggregates[18]. Therefore, SFRCAC has great potential for application in structural members if a balance between SFs content and RCA replacement ratio is achieved for the optimal mechanical performance of concrete, which will greatly improve the use of RCA in structural application. The effect of SFs on properties of RCAC, such as failure mode, compressive strength $\left(f_{c}\right)$, Young's modulus $\left(E_{c}\right)$, critical strain $\left(\varepsilon_{c}\right)$ and stress-strain relationship may be different from NCAC. However, there is a lack of research pertaining to the coupling effect of RCA and SFs on SFRCAC under compression.

The highlight of this paper is all specimens have equivalent cubic compressive strength $\left(f_{c u}\right)$ although the addition of RCA replacement ratio $\left(r_{g}\right)$ and SFs volume content $\left(v_{f}\right)$ are different. The objectives of this study are: (1) to evaluate the effect of $r_{g}$ and $v_{f}$ on the $f_{c u}, f_{c}, E_{c}$ and $\varepsilon_{c}$ of SFRCAC; (2) to quantify the effect of $r_{g}$, $v_{f}$ and their combined effect on the stress-strain relation of RCAC; (3) to characterize the crack pattern of SFRCAC specimens under compression. This investigation will be of significance for engineering practice and will provide a necessary data base for the further study of design methodology of RCAC structures. The experimental program and the result of the study are outlined in the following sections. 


\section{Notation of abbreviations and symbols}

$\begin{array}{ll}\text { NCA } & \text { Natural coarse aggregate } \\ \text { NCAC } & \text { Natural coarse aggregate concrete } \\ \text { RCA } & \text { Recycled coarse aggregate } \\ \text { RCAC } & \text { Recycled coarse aggregate concrete } \\ \text { SFs } & \text { Steel fibers } \\ \text { SFNCAC } & \text { Steel fiber reinforced natural coarse aggregate concrete } \\ \text { SFRCAC } & \text { Steel fiber reinforced recycled coarse aggregate concrete } \\ d_{f} & \text { Diameter of steel fibers } \\ l_{f} & \text { Length of steel fibers } \\ \lambda_{f} & \text { Characteristic coefficient of steel fiber } \\ v_{f} & \text { Steel fibers volume content, } \% \\ r_{g} & \text { Recycled coarse aggregate replacement ratio, } \% \\ f_{c} & \text { Prism compressive strength, MPa } \\ f_{c u} & \text { Cube compressive strength, MPa } \\ E_{c} & \text { Young's modulus of concrete, GPa } \\ d_{c} & \text { Critical deformation, mm } \\ E_{0} & \text { Tangent modulus at the origin point, GPa } \\ E_{p} & \text { Secant modulus at the peak point, GPa } \\ l_{0} & \text { Gauge length } \\ W_{1,0} & \text { Compression work } \\ R_{e, 1.0} & \text { Toughness index } \\ \varepsilon_{c} & \text { Critical strain corresponding to the peak stress of SFRCAC } \\ \varepsilon_{0} & \text { Critical strain corresponding to the peak stress of NCAC }\end{array}$

\section{Experimental Program}

\subsection{Materials and Mixture Proportion}

Portland cement (P.O 42.5) was used in all mixtures. RCA was made of waste mix-ready concrete specimens obtained from a concrete testing station; the strength and age of these waste concrete were unknown. The waste concrete was crushed through a jaw crusher, and then sieved. The NCA was crushed limestone. Detailed properties of RCA and NCA are shown in Table 1. Compared to NCA, RCA had lower specific gravity, higher water absorption and higher porosity. The particle size 
distribution of coarse aggregates obtained as result of the sieve analysis is presented in Fig.1.The fine aggregate was river sand with a fineness modulus of 2.67 and apparent density of $2556 \mathrm{~kg} / \mathrm{m}^{3}$. The water reducing agent was polycarboxylate plasticizer, the optimum dosage is $1 \%$ of cement (by weight) and the water-reducing ratio is $25 \%$. The plasticizer was used to ensure all the concrete mixtures had similar slump. All aggregates were used in the air-dry condition. The SFs were hooked at both ends, and has tensile strength of $1000 \mathrm{MPa}$, mean diameter $\left(d_{f}\right)$ of $0.6 \mathrm{~mm}$, mean length $\left(l_{f}\right)$ of $30.5 \mathrm{~mm}$, and aspect ratio $\left(l_{f} / d_{f}\right)$ of 54.6.

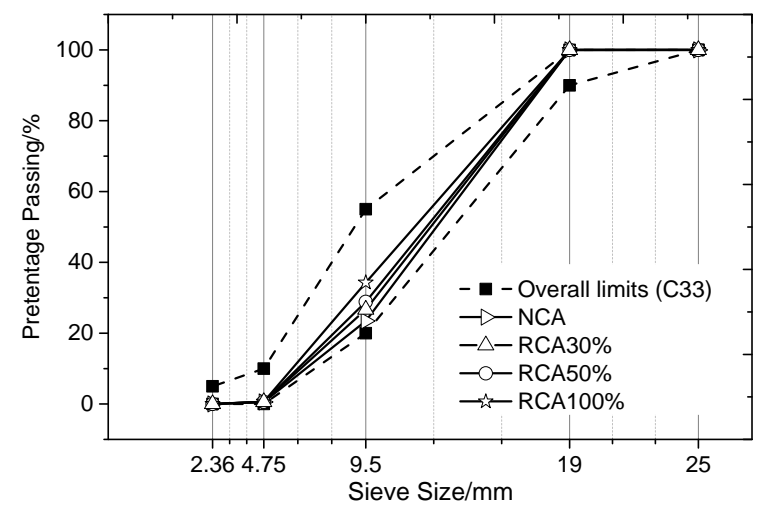

Fig.1.Particle size distribution of coarse aggregates

\section{Table 1}

Physical Property of the RCA and NCA

\begin{tabular}{cccccc}
\hline $\begin{array}{c}\text { Aggregate } \\
\text { type }\end{array}$ & $\begin{array}{c}\text { Apparent density } \\
\left(\mathrm{kg} / \mathrm{m}^{3}\right)\end{array}$ & $\begin{array}{c}\text { Bulk density } \\
\left(\mathrm{kg} / \mathrm{m}^{3}\right)\end{array}$ & $\begin{array}{c}\text { Water absorption } \\
(\mathrm{wt} \%)\end{array}$ & $\begin{array}{c}\text { Crush index } \\
(\%)\end{array}$ & $\begin{array}{c}\text { Porosity } \\
(\%)\end{array}$ \\
\hline RCA & 2640 & 1412 & 4.85 & 17.7 & 50.3 \\
NCA & 2814 & 1630 & 1.40 & 8.80 & 44.3 \\
\hline
\end{tabular}

RCA replacement ratio $\left(r_{g}\right)$ was defined as the mass ratio of RCA to overall coarse aggregate, where $r_{g}=0,30 \%, 50 \%, 100 \%$ respectively. SFs volume content $\left(v_{f}\right)$ was taken as $0,0.5 \%, 1 \%, 1.5 \%, 2 \%$ respectively. Eight group specimens in this research achieved same target compressive strength $\left(f_{c u}=45 \mathrm{MPa}\right)$ by adjusting the mixture 
design. Details of mixture proportion are listed in Table 2.

Table 2

Mix proportions of SFRCAC

\begin{tabular}{ccccccccc}
\hline Group & w/c & $\begin{array}{c}\text { Water } \\
\left(\mathrm{kg} / \mathrm{m}^{3}\right)\end{array}$ & $\begin{array}{c}\text { Cement } \\
\left(\mathrm{kg} / \mathrm{m}^{3}\right)\end{array}$ & $\begin{array}{c}\text { NCA } \\
\left(\mathrm{kg} / \mathrm{m}^{3}\right)\end{array}$ & $\begin{array}{c}\text { RCA } \\
\left(\mathrm{kg} / \mathrm{m}^{3}\right)\end{array}$ & $\begin{array}{c}\text { Fine aggregate } \\
\left(\mathrm{kg} / \mathrm{m}^{3}\right)\end{array}$ & $\begin{array}{c}\text { SFs } \\
\left(\mathrm{kg} / \mathrm{m}^{3}\right)\end{array}$ & $\begin{array}{c}\text { Water reducer } \\
\left(\mathrm{kg} / \mathrm{m}^{3}\right)\end{array}$ \\
\hline CR0F1 & 0.41 & 166 & 405 & 1121 & 0 & 740 & 78 & 4.05 \\
CR30F1 & 0.40 & 169 & 422 & 735 & 315 & 737 & 78 & 4.22 \\
CR50F1 & 0.39 & 170 & 437 & 506 & 506 & 737 & 78 & 4.37 \\
CR100F1 & 0.365 & 175 & 480 & 0 & 938 & 747 & 78 & 4.79 \\
CR50F0 & 0.39 & 158 & 406 & 553 & 553 & 769 & 0 & 4.06 \\
CR50F0.5 & 0.39 & 164 & 421 & 527 & 527 & 749 & 39 & 4.21 \\
CR50F1.5 & 0.39 & 177 & 454 & 506 & 506 & 754 & 117 & 4.54 \\
CR50F2 & 0.39 & 183 & 469 & 473 & 473 & 725 & 156 & 4.69 \\
\hline
\end{tabular}

Note: CR50F1means the specimen with $r_{g}=50 \%$ and $v_{f}=1 \%$.

\subsection{Specimen Preparation}

SFRCAC was mixed through a shaft mixer. First, all aggregates and SFs were put together and mixed for 2 minutes to ensure the SFs were uniformly dispersed. Then cement was added and mixed for another minute. Finally, water and water reducing agent were added together and mixed for another $2 \mathrm{~min}$. No segregation or bleeding of concrete or balling of SFs was observed in any of the eight mixtures.

The slump of fresh concrete was tested right after the mixing process. For each group, three $150 \mathrm{~mm} \times 150 \mathrm{~mm} \times 150 \mathrm{~mm}$ cubic specimens were cast for test of $f_{c u}$, nine $150 \mathrm{~mm} \times 150 \mathrm{~mm} \times 300 \mathrm{~mm}$ prism specimens were cast for tests of $f_{c}, E_{c}$ and stress-stain curves. All specimens were cast using steel moulds and put on a vibration table for 20 seconds to ensure compaction, then demoulded after 24 hours and cured in a moisture room at approximately $95 \%$ relative humidity $(\mathrm{RH})$ and $20^{\circ} \mathrm{C}$ temperature. The tests were performed at 28 days age.

\subsection{Test procedures}


All the tests were carried on a servo-hydraulic closed-loop testing machine with capacity of $3000 \mathrm{kN}$. First, cube specimens and prism specimens were tested at a loading rate of $0.6 \mathrm{MPa} / \mathrm{s}$ to failure to obtain $f_{c u}$ and $f_{c}$. Three specimens for each group were used and their mean value was taken as the test result of this group. Secondly, prism specimens were tested for $E_{c}$ and stress-strain curves following Chinese Standard GB/T50081[19].Two displacement transducers were attached to the opposite sides of the test section of the prism specimen to measure the deformation. The measured load and deformation were recorded with a data acquisition system at a rate of once per second. The test setup is shown in Fig.2. The compression specimens were preloaded to ensure axial loading. Load climbed steadily with rate of $0.6 \mathrm{MPa} / \mathrm{s}$ from zero to $f_{c} / 3$ and then unloaded with the same load rate to $0.5 \mathrm{MPa}$, forming one loading-unloading cycle. More than three loading-unloading cycles were applied on the specimens. The preload should be ended when the difference of values between the two opposite displacement transducers was less than $15 \%$. After the preloading process, the specimen was loaded at the same load rate to failure.

There had three stages for the test of complete stress-strain curve, that is, the same pre-loading method with the Elastic modulus test and the preload stress below $0.4 f_{c}$ to ensure the axial compression; then loaded to the ultimate load with force control at a rate of $0.6 \mathrm{MPa} / \mathrm{s}$; finally changed to displacement control at a rate of $0.1 \mathrm{~mm} / \mathrm{min}$ to obtain a stable descending stage. The whole testing process stopped when the load dropped to $30 \%$ of the peak load. 


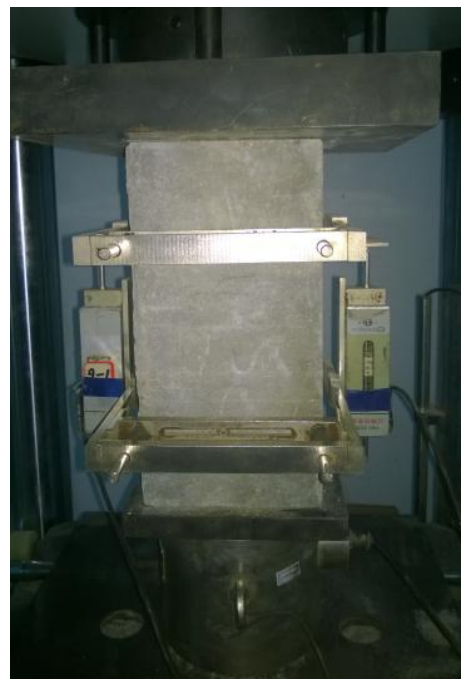

Fig.2. Test setup

\section{Test Results and discussion}

The obtained slump, $f_{c u}, f_{c}, E_{c}, \varepsilon_{\mathrm{c}}$ and critical deformation $\left(d_{c}\right.$, which is the deformation corresponding to the peak load on the load-deformation curves) of each group are listed in Table 3. Each value in the table is an average of the test results from three specimens.

Table 3

Test results

\begin{tabular}{cccccccc}
\hline Group & Slump/mm & $f_{c u} / \mathrm{MPa}$ & $f_{c} / \mathrm{MPa}$ & $d_{c} / \mathrm{mm}$ & $E_{c} / \mathrm{GPa}$ & $R_{e, 1.0}$ & $\varepsilon_{\mathrm{c}}\left(\times 10^{-3}\right)$ \\
\hline CR0F1 & 64 & 45.4 & 37.4 & 0.305 & 33.0 & 0.736 & 2.03 \\
CR30F1 & 58 & 46.0 & 40.2 & 0.343 & 34.6 & 0.671 & 2.29 \\
CR50F1 & 59 & 46.8 & 41.7 & 0.367 & 38.4 & 0.602 & 2.45 \\
CR100F1 & 53 & 47.2 & 43.6 & 0.436 & 37.8 & 0.598 & 2.91 \\
CR50F0 & 65 & 44.9 & 34.5 & 0.272 & 29.7 & 0.422 & 1.81 \\
CR50F0.5 & 62 & 45.6 & 38.0 & 0.319 & 34.0 & 0.529 & 2.13 \\
CR50F1.5 & 55 & 48.1 & 43.2 & 0.386 & 41.9 & 0.653 & 2.57 \\
CR50F2 & 49 & 49.9 & 44.6 & 0.428 & 42.9 & 0.657 & 2.85 \\
\hline
\end{tabular}

Note: $R_{e, 1.0}$ stands for toughness index.

\subsection{Load-deformation curves}

Load-deformation curves of SFRCAC obtained from the tests are shown in Fig.3. It 
can be seen that the load-deformation curves of SFRCAC mainly consist of three characteristic parts. The first part of curves is the linear portion, which means the material property submits to Hooke's law within the limit of proportionality. The second part of the curves is the nonlinear portion of the ascending branch which terminates at the peak point, the slope of curve decreases continuously at this stage. The descending branch is the third part of curve, the load reduces continuously with the increase of deformation at this stage. It is also found from the test that the shape of SFRCAC load-deformation curve is similar to that of SFNCAC, this similar result can be found in previous research[16], but, the key points on the curves are different with the change of $v_{f}$ and $r_{g}$.

The complete load-deformation curves of SFRCAC with different $r_{g}$ and same $v_{f}$ of $1 \%$ are compared in Fig.3(a). It can be seen from the figure that both peak load and critical deformation increase progressively with the increase of $r_{g}$. Higher $r_{g}$ could lead to higher $d_{c}$, which is consistent with published results[20, 21]. When $r_{g}=0$, the ascending portion is steeper and transition area is wider compared to the other three curves, which indicates that the compressive energy dissipation capacity of concrete decreases with introducing RCA.

Load-deformation curves of SFRCAC with different $v_{f}$ and same $r_{g}$ of $50 \%$ are shown in Fig.3 (b). It can be seen from the figure that with the increase of $v_{f}$, both peak load and critical deformation of SFRCAC increase significantly. The ascending branches of these curves are similar but the slope of descending branches are somewhat less steep with the increase of $v_{f}$. This means that the compressive energy 
dissipation capacity of concrete increases with the increase of $v_{f}$, the addition of SFs can significantly improve the post-peak deformability of RCAC.

The most significant effect of adding SFs is to improve the toughness of concrete. Compression work $\left(W_{1.0}\right)$ and toughness index $\left(R_{e, 1.0}\right)$ can be used to evaluate the axial compression toughness of steel fiber reinforced concrete[22], where $W_{1.0}$ is defined as the area under the load-deformation curve with the deformation range from 0 to $l_{0} \times 1.0 \%, l_{0}$ is gauge length $\left(l_{0}=150 \mathrm{~mm}\right.$ in this study). $W_{1.0}$ is an indicator of the energy absorption capacity of specimen. $R_{e, 1.0}$ is defined by the following equation:

$$
R_{e .1 .0}=\frac{W_{1.0}}{F_{\max } \times l_{0} \times 1.0 \%}
$$

Where, $F_{\max }$ is peak load.

In this study, $R_{e, 1.0}$ was calculated to measure the reinforcement effect of SFs, the calculating results of $R_{e, 1.0}$ for each group is listed in Table.3. When $v_{f}$ increases from 0 to $2 \%, R_{e, 1.0}$ increases from 0.422 to 0.657 , increasing ratio reaches $55.6 \%$, which indicates SFs can remarkably improve the toughness and energy absorption capability of SFRCAC. Toughness and behavior of SFRCAC under compression becomes similar to those of SFNCAC and similar results were reported[16]. But when $v_{f}=1 \%$ and $r_{g}$ increases from 0 to $100 \%, R_{e, 1.0}$ decreases from 0.736 to 0.598 , this indicates that the toughness and energy absorption capability of SFRCAC degrade with the addition of RCA. 


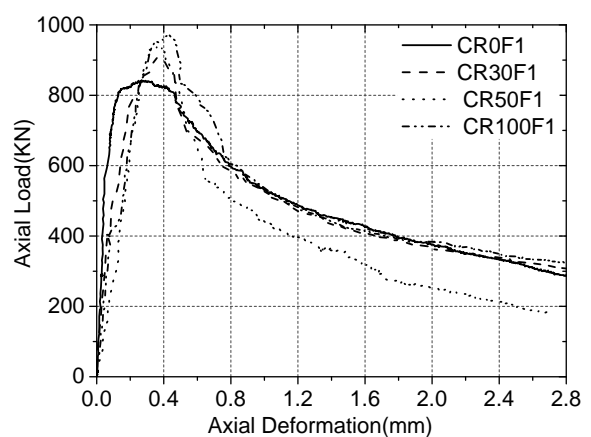

(a)

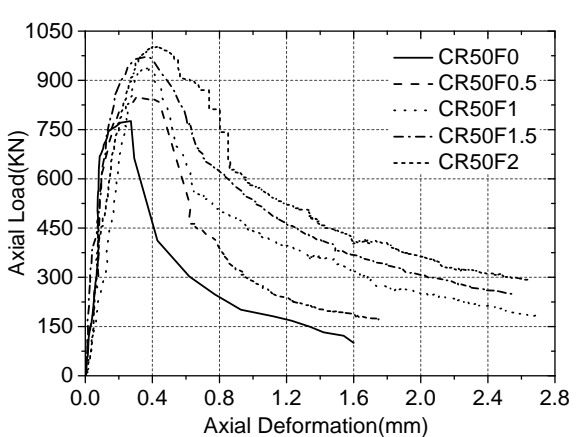

(b)

Fig.3 Load-deformation curve of SFRCAC; (a) with different RAC replacement ratio ( $v_{f}=1 \%$ ); (b) with

different SFs volume content $\left(r_{g}=50 \%\right)$

\subsection{Compressive strength}

The compressive strength is the peak stress obtained during the compressive test on specimens. $f_{c u}$ and $f_{c}$ obtained from the tests are listed in Table 3, both $f_{c u}$ and $f_{c}$ increases with the increase of $v_{f}$ and $r_{g}$.

When $r_{g}=50 \%, f_{c u}$ increases from $44.9 \mathrm{MPa}$ to $49.9 \mathrm{MPa}$ and $f_{c}$ increases from $34.5 \mathrm{MPa}$ to $44.6 \mathrm{MPawith}$ the increase of $v_{f}$ from 0 to $2 \%$, increasing ratio is $11 \%$ and $29 \%$, respectively. With the reinforcement of SFs, the RCAC and NCAC have the similar compressive behavior, SFs have better effect on RCAC than that on NCAC, which is similar to previous research[16].

When $v_{f}=1 \%, f_{c u}$ increases from $45.4 \mathrm{MPa}$ to $47.2 \mathrm{MPa}$ and $f_{c}$ increases from 37.4MPa to $43.6 \mathrm{MPawith}$ the increase of $r_{g}$ from 0 to $100 \%$, increasing ratio is $6 \%$ and $16 \%$, respectively. This phenomenon is different from the previously published results that compressive strength had decreasing trend with the increase of RCA [9, 20,23]. There are probably two reasons which can explain the results of this research. 
One reason is that a new mix proportion method was used here to ensure the 8 group specimens had similar compressive strength[24], at the same time RCA provides better hydration in the interfacial transition zone (ITZ) due to the high water absorption. The other reason is that specimens in this paper are reinforced by SFs. SFs not only can provide the bridging effect to prevent the micro-crack expansion but also can promote hydration reaction of surrounding paste due to the fact that reaction heat can be conducted out faster. The cement matrix microstructure of RCAC with different SFs content is shown in Fig.4, which shows that the hydrated reaction is more complete with higher SFs content.

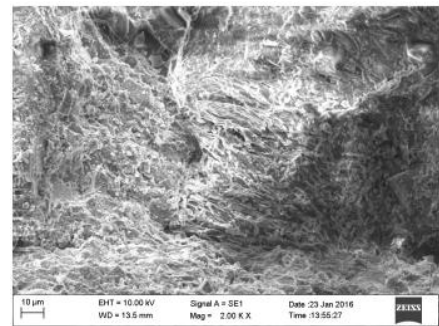

(a)

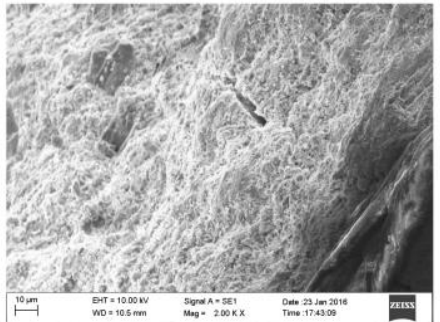

(b)

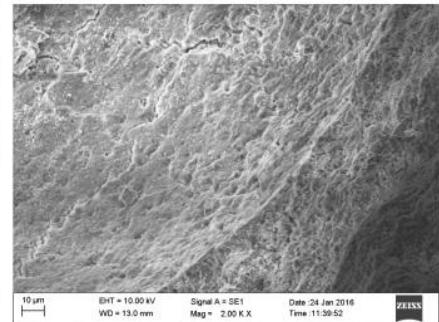

(c)

Fig.4 Representative SEM images of SFRCAC (a) $v_{f}=0 \%$; (b) $v_{f}=1 \%$; (c) $v_{f}=2 \%$

In some countries, such as China, $f_{c u}$ is usually required in the building standards and is the basic value to determine the concrete strength [19]. However, $f_{c}$ is usually used in engineering design. So it is necessary to establish a theoretical relation between $f_{c}$ and $f_{c u}$.

Test results of $f_{c}$ and $f_{c u}$ from this paper and previous research [20, 21,25-28] are drawn as scatter points in Fig.5. Obviously, the test results between $f_{c}$ and $f_{c u}$ is similar linearity. A formula between $f_{c}$ and $f_{c u}$ is proposed through the regression of test data, as flowing: 


$$
f_{c}=0.86 f_{c u}-0.18
$$

The value of $f_{c}$ calculated by Equation (2) based on the experimental value of $f_{c u}$ from previous research [20, 21,25-28] on recycled concrete aggregate was compared with the experimental value of $f_{c}$ in Fig.6. Although mix proportion designs of specimens are different from the different experiments, the calculated value matches the experimental value well. Equation (2) can be used to calculate $f_{c}$ of SFRCAC.
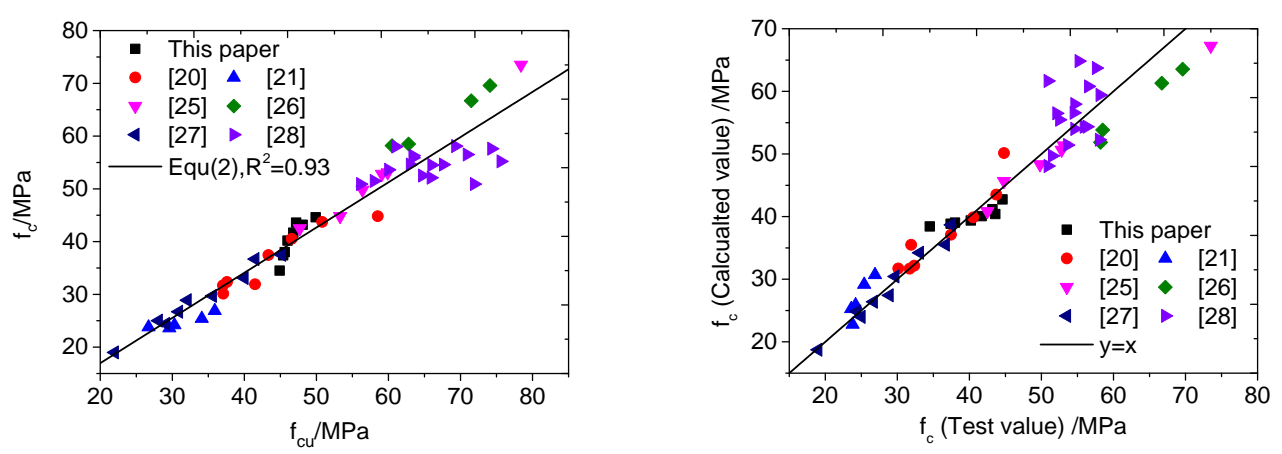

Fig.5. Relationship between $f_{c}$ and $f_{c u}$ Fig.6. Value compare of $f_{c}$ between test and calculated.

\subsection{Young's modulus}

Young's modulus is an important property of concrete and is extensively used to calculate deformation of structures. Young's modulus was evaluated according to GB/T50081-2002 (China Standard)[19] as follows:

$$
E_{c}=\frac{f_{c 2}-f_{c 1}}{\varepsilon_{c 2}-\varepsilon_{c 1}}
$$

Where, $f_{c 1}=0.5 \mathrm{MPa}, f_{c 2}=f_{c} / 3$; and $\varepsilon_{c 1}, \varepsilon_{c 2}$ are the compressive strain corresponding to $f_{c 1}, f_{c 2}$, respectively. Test results of $E_{c}$ are listed in Table 3 .

When $v_{f}=1 \%, E_{c}$ increases from $33 \mathrm{GPa}$ to $37.8 \mathrm{GPa}$ with the increases of $r_{g}$ from 0 to $100 \%$, with the maximum value of $38.4 \mathrm{GPa}$ at $r_{g}=50 \%$. This is attributed to the fact that the particles of RAC are somewhat finer than that of NAC in this study, 
as shown in Fig.1. With the partial replacement of NCA with RCA, the grading of coarse aggregate can be improved, and thus, a denser concrete is achieved. As a result, RCAC exhibits a higher Young's Modulus than that without RCA and its maximum value appears at $r_{g}=50 \%$. Previous studies show that the effects of RCA on $E_{c}$ are different. No significant change of $E_{c}$ was observed by substitution of RCA for NCA [16]. $E_{c}$ of RCAC decreased with the increase of $r_{g}$, when $r_{g}=100 \%$, the reduction ratio of $E_{c}$ reached to $23.6 \%$ [20].

SFs has significant reinforcing effect on $E_{c}$. When $r_{g}=50 \%$, with the increase of $v_{f}$ from 0 to $2 \%, E_{c}$ increases from $29.7 \mathrm{GPa}$ to $42.9 \mathrm{GPa}, E_{c} / f_{c u}$ ranges from 0.66 to 0.871 , achieving its maximum value of 0.871 at $v_{f}=1.5 \%$. The results are similar with that by Marčiukaitis et al. $\left(l_{f} / d_{f}=50\right)$ [12]. This indicates that the effect of $v_{f}$ on $E_{c}$ of SFRCAC is not the more the better, but instead has an optimum content, in this study the best SFs content is $1.5 \%$.

SFs and RCA also have a combined effect on the Young's modulus of SFRAC which is similar to the effect on compressive strength. Based on the experimental data from this study and previous studies $[7,10,16,20,23,29,30]$, the relationship between $E_{c}$ and $f_{c}$ are drawn as scatter points in Fig.7. Overall, $E_{c}$ increases with the increase of $f_{c}$. A formula of $E_{c}$ is proposed based on the regression of test data, as shown in Equation (4).

$$
E_{c}=0.88 f_{c}-0.7
$$

Equation (4) is suitable for predicting $E_{c}$ of SFRCAC when $f_{c}$ is less than 50MPa. Fig. 8 shows the comparison of the calculated value with test data. It can be seen from 
the figure that the calculated results matches the experimental data well.
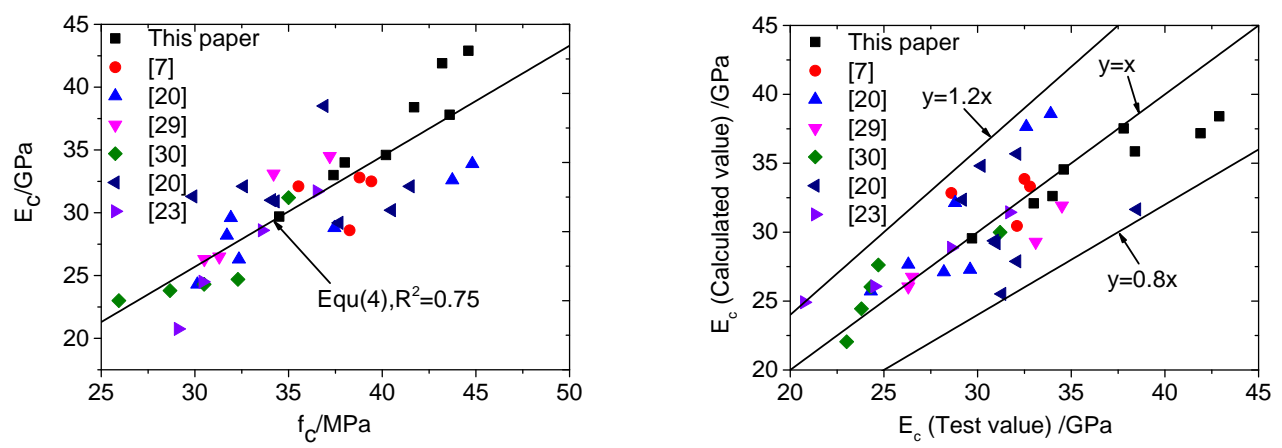

Fig.7. Relationship between $f_{c}$ and $E_{c} \quad$ Fig.8. Value compare of $E_{c}$ between test and calculated.

\subsection{Critical strain}

The critical strain $\left(\varepsilon_{\mathrm{c}}\right)$ is defined as the strain corresponding to the peak stress on the stress-strain curve, which could evaluate the deformability of specimen. Test results of $\varepsilon_{\mathrm{c}}$ are shown in Table.3. Generally $\varepsilon_{\mathrm{c}}$ increases with the increase of $f_{c}$. With similar $f_{c}$, both $v_{f}$ and $r_{g}$ can cause the increase of $\varepsilon_{\mathrm{c}}$.

In order to analysis the effect of SFs and RCA on $\varepsilon_{\mathrm{c}}$, the relationship between the increase ratio of $\varepsilon_{\mathrm{c}}$ and $\lambda_{f}, r_{g}$ is shown in Fig.9, according to the test results, in which $\lambda_{f}$ is character coefficient of SFs, $\lambda_{f}=v_{f} l_{f} / d_{f}$. The critical strain ratio, which is the critical strain of SFRCAC to that of NCAN having the same mix design as SFRCAC except the different $r_{g}$, was calculated based on test data originally from this paper and previous literatures.

It can be seen that $\varepsilon_{\mathrm{c}}$ increases with increase of $r_{g}$, the previous study also proved this conclusion [2]. The main reason for the increase of $\varepsilon_{\mathrm{c}}$ is that RCA has higher void and lower density. Quantity of cement paste matrix in RCAC is much higher than NCAC because of the inherent existence of old cement paste matrix in RCA. When $r_{g}$ 
reaches $100 \%$, the increase ratio of critical strain were 5.5\%[31], 20\%[32], 20.5\% [20], respectively. SFs have similar increasing effect on $\varepsilon_{\mathrm{c}}$ of RCAC and NCAN, but increasing effect on RCAC is higher than that on NCAN [26, 33-37]. Obviously, with the combined effect of SFs and RCA the increase rate of $\varepsilon_{\mathrm{c}}$ is bigger than the other, the biggest increase ratio of $\varepsilon_{\mathrm{c}}$ reaches $40 \%$ in this study.

Based on the test results from this paper, an empirical formula of $\varepsilon_{\mathrm{c}}$ is put forward to take into account effect of SFs and RCA, as shown in Equation (5):

$$
\varepsilon_{\mathrm{c}} / \varepsilon_{0}=\left(1+0.37 \lambda_{f}\right)\left(1+0.22 r_{g}\right)
$$

Where, $\varepsilon_{c}$ is the critical strain of SFRCAC; $\varepsilon_{0}$ is the critical strain of NCAC; When $\varepsilon_{0}$ is known, $\varepsilon_{c}$ can be estimated by Equation (5). Using the empirical formula of $\varepsilon_{0}=\left(0.7+0.172 \sqrt{f_{c}}\right) \times 10^{-3}[38], f_{c}$ is compressive strength of NCAC (in MPa), $\varepsilon_{c}$ can be calculated by Equation(6):

$$
\varepsilon_{0}=\left(0.7+0.172 \sqrt{f_{c}}\right)\left(1+0.32 \lambda_{f}\right)\left(1+0.22 r_{g}\right) \times 10^{-3}
$$

When $f_{c}$ is known, $\varepsilon_{c}$ can be estimated by Equation (6). Compare of $\varepsilon_{c}$ calculated by Equation (5) and (6) with the test results is shown in Fig.10. It can be seen that the calculation results are in good agreement with test data. 

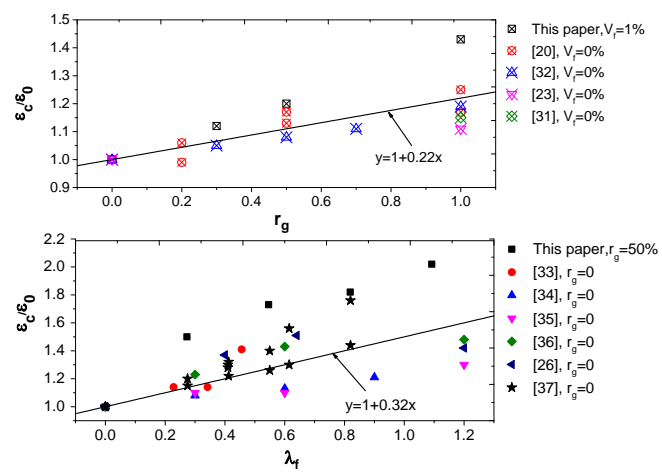

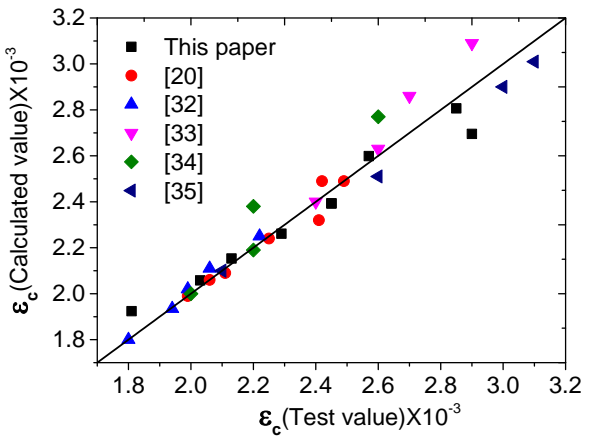

Fig. 9. Relationship of $\varepsilon_{c} / \varepsilon_{0}$ with $r_{s}$ and $\lambda_{f}$ Fig.10. Value compare of $\varepsilon_{c}$ between test and calculated.

\subsection{Stress-strain relation}

The basic character of the stress-strain curves are consistent with the load-deformation curves which have been analyzed in the previous section. In order to make the research of the stress-strain curve based on the same foundation, the stress-strain curves are transformed into the dimensionless form, as shown in Fig.11.

As shown in Fig.11(a), the ascending branches of stress-strain curves are very close for the specimens with different $v_{f}$. This indicates that the stiffness of SFRCAC before peak load is mainly affected by concrete matrix instead of SFs reinforcement. However, with the increase of $v_{f}$, descending branch of the curve becomes flatter, this proves that SFs leads to significant improvement in deformability after peak load, As shown in Fig.11(b), RCA has significant impact on the entire curve. At ascending portion, the stress-strain curve of concrete without RCA is steeper than that adding RCA. Although $r_{g}$ is different, the other three curves almost overlap together before peak point. At descending stage, stress-strain curve becomes steeper when $r_{g}$ increases from 0 to $50 \%$, but the curve has little change when $r_{g}$ increases from 50\% to $100 \%$. 


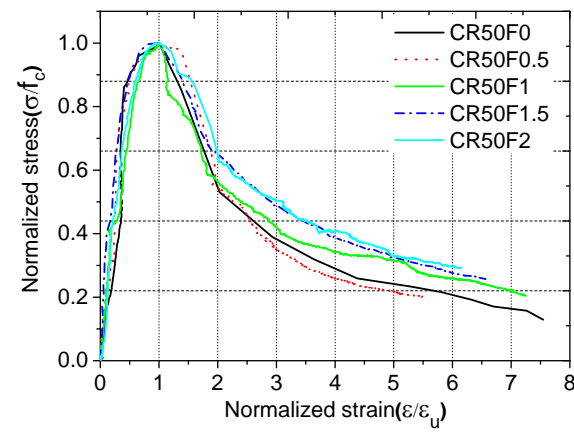

(a)

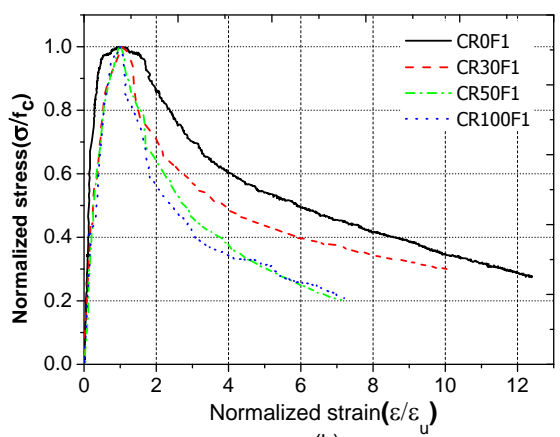

(b)

Fig.11. Normalized stress-strain curve of SFRCAC obtained from the tests

(a) with different SFs content;(b) with different RCA replacement ratio

Mathematical character of typical normalized stress-strain curve including original point $(x=0, y=0)$, ascending portion $\left(0 \leq x<1, \frac{d^{2} y}{d x^{2}}<0\right.$, curve slope decreased), peak point $\left(x=1, y=1, \frac{d y}{d x}=0\right)$, inflection point of decreasing portion $\left(x>1, \frac{d^{2} y}{d x^{2}}=0\right)$, maximum curvature point of decreasing portion $\left(x>1, \frac{d^{3} y}{d x^{3}}=0\right)$. These characters of stress-strain curves of SFRCAC are similar with those of common concrete. So the constitutive model of NCAC can be extended to SFRCAC. In order to obtain accurate stress-strain fitting curve, many functional forms, such as polynomial, exponential function, trigonometric functions, rational fraction, were used in previous researches[12, 15, 39-42]. Two of these models were chosen to express the stress-strain curve of SFRCAC.

One constitutive model[41]is as follows:

$$
y=\left\{\begin{array}{l}
\frac{\xi x-x^{2}}{1+(\xi-2) x} ; 0 \leq x \leq 1 \\
\frac{x}{\psi(x-1)^{2}+x} ; x>1
\end{array}\right.
$$


Where, $x=\varepsilon / \varepsilon_{c}, y=\sigma / f_{c},\left.\frac{d \mathrm{y}}{d x}\right|_{x=0}=\xi=\left.\frac{d \sigma / d f_{c}}{d \varepsilon / d \varepsilon_{u}}\right|_{x=0}=\frac{E_{0}}{E_{p}}, \xi$ is the ratio of tangent modulus at the origin point $\left(E_{0}\right)$ to the secant modulus at the peak point $\left(E_{p}\right)$ and a parameter related to the curvature of the ascending portion. $\psi$ is the parameter related to descending branch, when $\psi=0, y=1$, the curve is horizontal line, which means the concrete is totally plastic after peak point; when $\psi=\infty, y \equiv 0$, the curve is vertical line, which means the concrete is totally brittle after peak point. The bigger of the $\psi$ value, the brittle of the concrete after peak point.

The advantage of Equation(7) is that parameters have clear physical meaning, but the functional form is complicated piecewise function. Comparatively constitutive model proposed by Ezeldin and Balagaru [42] is more brief,

$$
y=\frac{\beta x}{\beta-1+x^{\beta}}
$$

Where, $x=\varepsilon / \varepsilon_{c}, y=\sigma / f_{c}, \beta$ is the only parameter determined by material.

The value of $\xi 、 \psi$ and $\beta$ is determined by experimental stress-strain curve of SFRCAC and the relationship between $\xi 、 \psi, \beta$ and $\lambda_{f}, r_{g}$ is shown in Fig.12.It can be seen that $\xi$ increase with the increase of $\lambda_{f}$, rapidly decreases when $r_{g}$ increase from 0 to $50 \%$. Compared to $\lambda_{f}, \xi$ is more sensitive to $r_{g} \cdot \psi$ and $\beta$ increase with increasing of $r_{g}$ and decreasing of $\lambda_{f}$. 


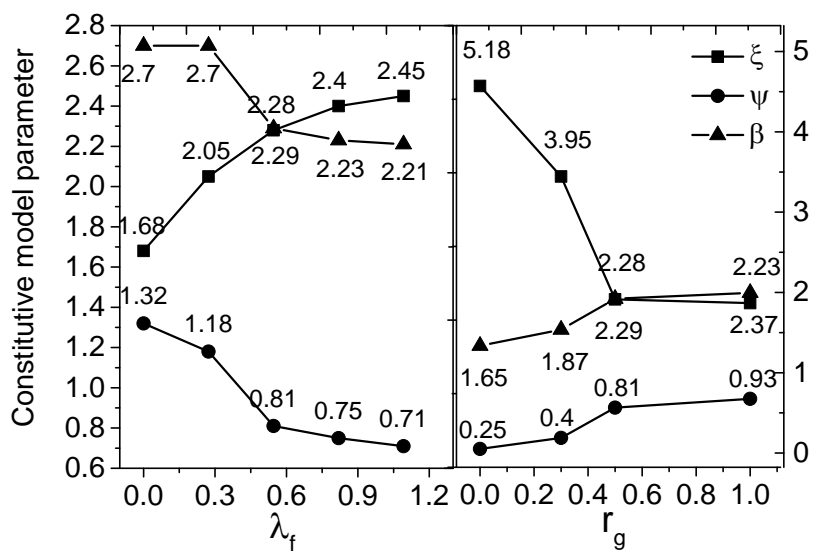

Fig.12. Relationship of constitutive model parameters with $\lambda_{f}$ and $r_{g}$

According to the above analysis, the regression equation of $\xi 、 \psi 、 \beta$ is set up by using $\lambda_{f}$ and $r_{g}$ as variables, as follows.

$$
\begin{gathered}
\xi=3.92+0.7 \lambda_{f}-3.2 r_{g}, R^{2}=0.44 \\
\psi=0.75-0.6 \lambda_{f}+0.78 r_{g}, R^{2}=0.53 \\
\beta=2.15-0.53 \lambda_{f}+0.81 r_{g}, R^{2}=0.44
\end{gathered}
$$

$\xi 、 \psi$ and $\beta$ can be calculated by Equation (9) and Equation (10), then the fitted stress-strain curve can be determined by Equation (7) and Equation (8). The comparison of fitted curves with experimental curves is shown in Fig.13. It can be seen that ascending portion estimated by the two models is very close, but the descending portion estimated by Equation (7) is more accurate. Overall, fitted curves matches well with experimental curves. The constitutive model of NCAN still can be used to estimate the stress-strain curves of SFRCAC by using appropriate parameter values. 

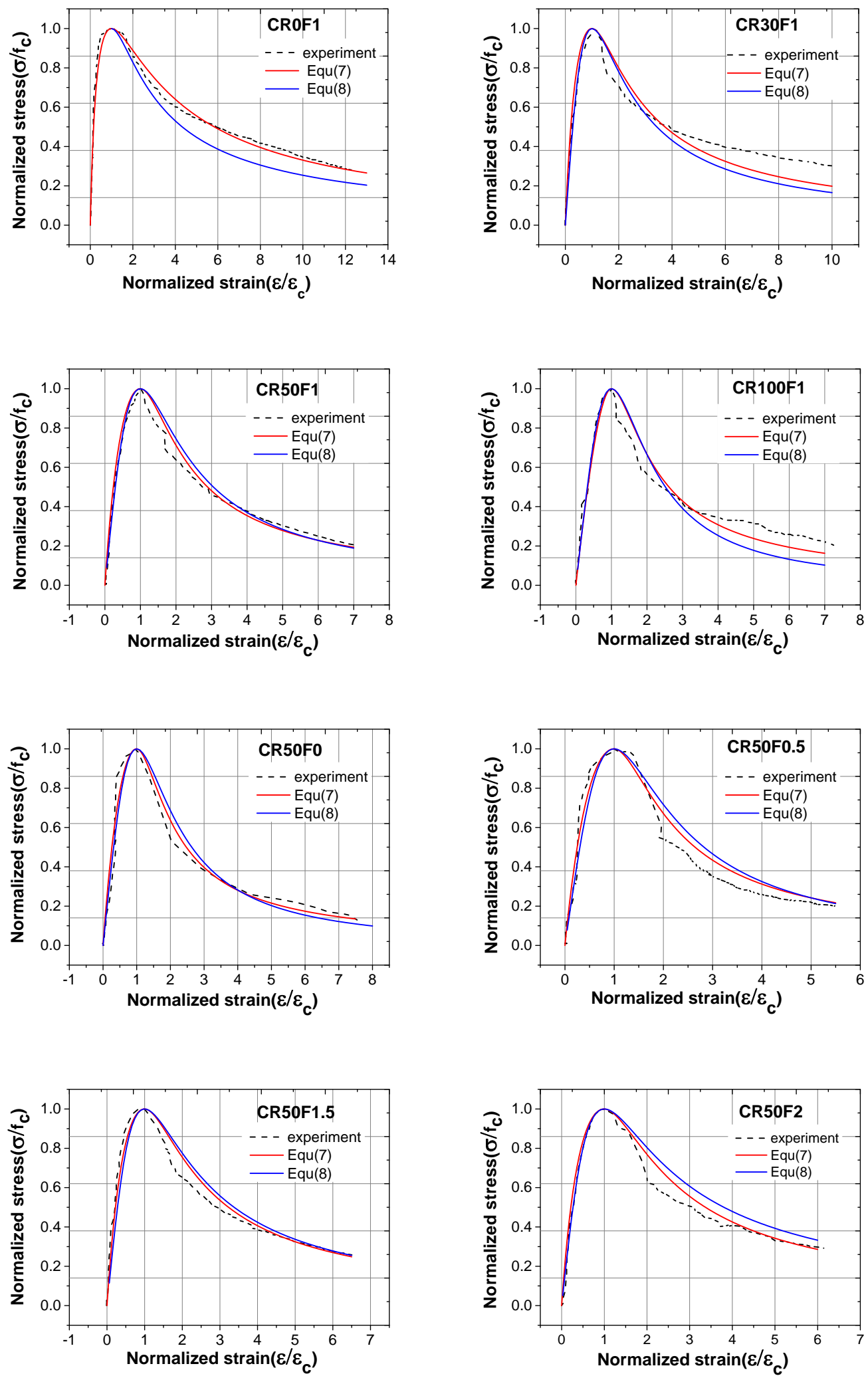

Fig.13.Comparison of calculated normalized stress-strain curve of SFRCAC with that from test

\subsection{Failure mechanism}


Compared to RCA, SFs has significant effect on the failure mode of SFRCAC. For the Group CR50F0, $r_{g}=50 \%$ and $v_{f}=0$, no visible cracks were observed in the early stage of loading. When approaching to the peak load, one crack or several longitudinal parallel cracks started to appear in the central portion of the specimen and then propagated quickly. Finally, specimen crushed locally and cracked, hardly maintained its integrity, the failure process was similar to NCAC.

For specimens with the SFs, with the increase of load, the first crack formed in the middle of specimen due to lateral expansion, and followed by other cracks appearing nearby. These cracks were parallel to the direction of force. At this moment, steel fibers perpendicular to the loading direction intercepted these cracks and offered some resistance to their growth. Later, diagonal cracks appeared in upper or lower portion of specimen. With the increase of load, diagonal cracks broadened and extended continuously, led to them connect with the cracks at the middle parts. At the same time, many small vertical cracks grew in the middle parts, resulting in the peeling of the surface of specimen. Finally, cracks extended to the other side of specimen. Loud noises were heard when SFs was being pulling out of the cement matrix at this stage. When the stress was beyond its peak value, the specimen did not break suddenly, maintained a good integrity at the end of testing.

After the compressive test, the angle of the main diagonal cracks was measured. The typical crack patterns of four samples with the same SFs volume content $\left(v_{f}=1 \%\right)$ are shown in Fig.14. The angle of the principal diagonal crack for specimens CR0F1 $\left(r_{g}\right.$ $=0), \mathrm{CR} 30 \mathrm{~F} 1\left(r_{g}=30 \%\right), \mathrm{CR} 50 \mathrm{~F} 1\left(r_{g}=50 \%\right)$ and CR100F1 $\left(r_{g}=100 \%\right)$ was about $65^{\circ}$, 
$75^{\circ}, 85^{\circ}$ and $90^{\circ}$ respectively. It is clear that the angle of main diagonal cracks increases with the increase of the RCA replacement ratio.

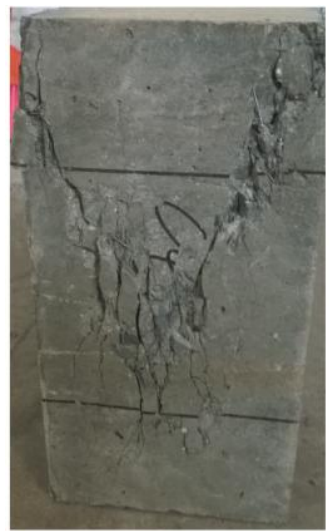

CROF1

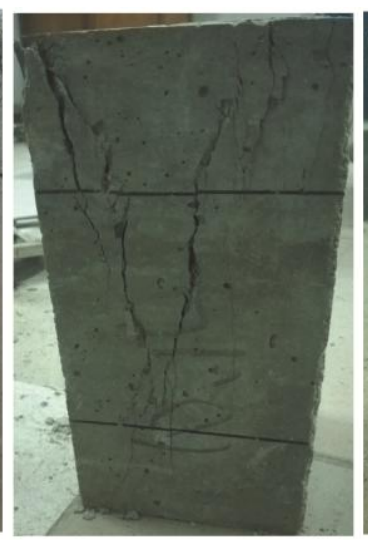

CR30F1

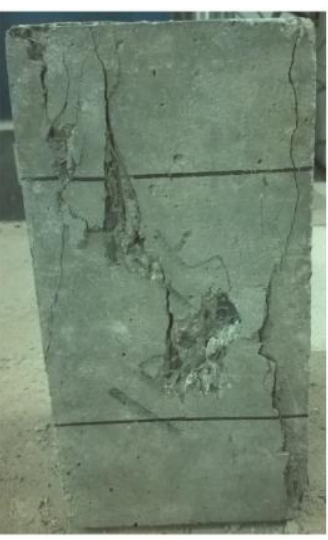

CR50F1

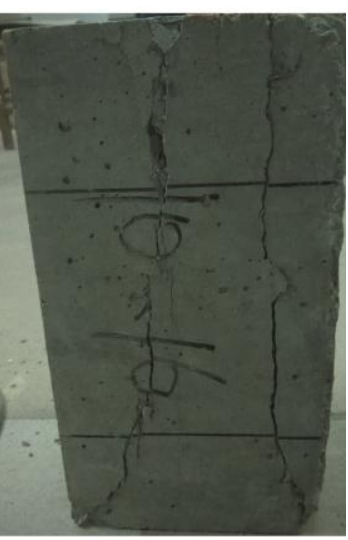

CR100F1

Fig.14. Typical crack pattern of specimens

\section{Conclusions}

The mechanical characteristics of concrete with different RCA replacement ratio and different SFs volume content have been experimentally studied through a compressive test. Based on the extensive test data and analysis, the following conclusions can be drawn:

1. Through reasonable mix proportion design and reinforcement with steel fibers, RCAC with different RCA replacement ratio can have similar compressive strength. Compared to NCAC, steel fibers have better reinforcing effect on RCAC. For the SFRCAC with equivalent compressive strength, its toughness index increases with steel fiber content and decreases with RCA replacement ratio.

2. With the equivalent compressive strength, Young's Modulus of SFRCAC achieves maximum value at $r_{g}=50 \%$, the best SFs content is $1.5 \%$. A 
calculation model of Young's Modulus is proposed by regression of experimental data.

3. The critical strain of SFRCAC significantly increases with the combined effect of SFs and RCA, the biggest increase ratio reaches to $40 \%$. An empirical formula is proposed to estimate the critical stain of SFRCAC.

4. The mathematical character of stress-strain curves of SFRCAC is similar with that of NCAC. The constitutive model of NCAN still can be used to estimate the stress-strain curves of SFRCAC by using appropriate parameter values. Stress-strain curves of SFRCAC can be estimated through Equation (7) to (10).

5. The failure of RCAC specimen is brittle with localized crushing. With the addition of SF, the RCAC specimen exhibits ductile failure and maintains their integrity during testing. Angles between the major diagonal crack and horizontal line increase with the increase of RCA replacement ratio.

\section{Acknowledgments}

The authors gratefully acknowledge the partially financial support of this work by the National Science Foundation of China under Grant Nos. 51379186 and 51522905. They also thank Miss Jingyun Lu and Mr. Zhaoqiang Yan for their participation in test program. The comments of Dr. Dongming Yan of Zhejiang University are also gratefully acknowledged.

\section{References}

[1] C.J. Zega, A.A. Di Maio, Recycled Concretes Made with Waste Ready-Mix Concrete as Coarse Aggregate, Journal of Materials in Civil Engineering 23(3) (2011) 281-286. 
[2] J. Xiao, W. Li, Y. Fan, X. Huang, An overview of study on recycled aggregate concrete in China (1996-2011), Construction and Building Materials 31 (2012) 364-383.

[3] V.W. Tam, X.F. Gao, C.M. Tam, K.M. Ng, Physio-chemical reactions in recycle aggregate concrete, Journal of hazardous materials 163(2-3) (2009) 823-8.

[4] P.L. Maier, S.A. Durham, Beneficial use of recycled materials in concrete mixtures, Construction and Building Materials 29 (2012) 428-437.

[5] I. Marie, H. Quiasrawi, Closed-loop recycling of recycled concrete aggregates, Journal of Cleaner Production 37 (2012) 243-248.

[6] C. Meyer, The greening of the concrete industry, Cement and Concrete Composites 31(8) (2009) 601-605.

[7] M. Etxeberria, E. Vázquez, A. Marí, M. Barra, Influence of amount of recycled coarse aggregates and production process on properties of recycled aggregate concrete, Cement and Concrete Research 37(5) (2007) 735-742.

[8] X. Li, Recycling and reuse of waste concrete in China, Resources, Conservation and Recycling 53(3) (2009) 107-112.

[9] M. Casuccio, M.C. Torrijos, G. Giaccio, R. Zerbino, Failure mechanism of recycled aggregate concrete, Construction and Building Materials 22(7) (2008) 1500-1506.

[10] L. Butler, J.S. West, S.L. Tighe, Effect of recycled concrete coarse aggregate from multiple sources on the hardened properties of concrete with equivalent compressive strength, Construction and Building Materials 47 (2013) 1292-1301.

[11] S.B. Huda, M. Shahria Alam, Mechanical and Freeze-Thaw Durability Properties of Recycled Aggregate Concrete Made with Recycled Coarse Aggregate, Journal of Materials in Civil Engineering 27(10) (2015) 04015003.

[12] G. Marčiukaitis, R. Šalna, B. Jonaitis, J. Valivonis, A model for strength and strain analysis of steel fiber reinforced concrete, Journal of Civil Engineering and Management 17(1) (2011) 137-145.

[13] A.A. Shah, Y. Ribakov, Recent trends in steel fibered high-strength concrete, Materials \& Design 32(8-9) (2011) 4122-4151.

[14] G. Appa Rao, A. Sreenivasa Rao, Toughness indices of steel fiber reinforced concrete under mode II loading, Materials and Structures 42(9) (2009) 1173-1184.

[15] S.-C. Lee, J.-H. Oh, J.-Y. Cho, Compressive Behavior of Fiber-Reinforced Concrete with End-Hooked Steel Fibers, Materials 8(4) (2015) 1442-1458.

[16] J.A. Carneiro, P.R.L. Lima, M.B. Leite, R.D. Toledo Filho, Compressive stress-strain behavior of steel fiber reinforced-recycled aggregate concrete, Cement and Concrete Composites 46 (2014) 65-72.

[17] S. Erdem, A.R. Dawson, N.H. Thom, Microstructure-linked strength properties and impact response of conventional and recycled concrete reinforced with steel and synthetic macro fibres, Construction and Building Materials 25(10) (2011) 4025-4036.

[18] S. Senaratne, D. Gerace, O. Mirza, V.W.Y. Tam, W.-H. Kang, The costs and benefits of combining recycled aggregate with steel fibres as a sustainable, structural material, Journal of Cleaner Production 112 (2016) 2318-2327.

[19] Standard for test method of mechanical properties on o rdinary concrete,GB/T50081, China, 2002.

[20] G.-F. Belén, M.-A. Fernando, C.L. Diego, S.-P. Sindy, Stress-strain relationship in axial compression for concrete using recycled saturated coarse aggregate, Construction and Building Materials 25(5) (2011) 2335-2342. 
[21] J. Xiao, J. Li, C. Zhang, Mechanical properties of recycled aggregate concrete under uniaxial loading, Cement and Concrete Research 35(6) (2005) 1187-1194.

[22] Standard test methods for fiber reinforced concrete. CECS13, China., Standards China, 2010, p. 48.

[23] P. Folino, H. Xargay, Recycled aggregate concrete - Mechanical behavior under uniaxial and triaxial compression, Construction and Building Materials 56 (2014) 21-31.

[24] D. Gao, L. Zhang, J. Lu, Z. Yan, Research on design parameters of mix proportion for recycled aggregate concrete, Journal of Architecture and Civil Engineering 33(1) (2016) 8-14.

[25] J.-h. Xie, Y.-c. Guo, L.-s. Liu, Z.-h. Xie, Compressive and flexural behaviours of a new steel-fibre-reinforced recycled aggregate concrete with crumb rubber, Construction and Building Materials 79 (2015) 263-272.

[26] F. Bencardino, L. Rizzuti, G. Spadea, R.N. Swamy, Stress-Strain Behavior of Steel Fiber-Reinforced Concrete in Compression, J. Mater. Civ. Eng 20(3) (2008) 255-263.

[27] N.A. Abdulla, Effect of Recycled Coarse Aggregate Type on Concrete, Journal of Materials in Civil Engineering 27(10) (2015) 04014273.

[28] H. Zhu, D. Gao, J. Tang, Strength Indexes of SF Reinforced High Strength Concrete and Their Interrelations, Journal of Building Materials 12(3) (2009) 323-327.

[29] M. Arezoumandi, A. Smith, J.S. Volz, K.H. Khayat, An experimental study on flexural strength of reinforced concrete beams with 100\% recycled concrete aggregate, Engineering Structures 88 (2015) 154-162.

[30] R.K. Choubey, S. Kumar, M. Chakradhara Rao, Modeling of fracture parameters for crack propagation in recycled aggregate concrete, Construction and Building Materials 106 (2016) 168-178.

[31] K. Rahal, Mechanical properties of concrete with recycled coarse aggregate, Building and Environment 42(1) (2007) 407-415.

[32] J. Xiao, Experimental Investigation on Complete Stress-Strain Curve of Recycled Concrete Under Uniaxial Loading, Journal of Tongji University( Natural Science) 35(11) (2007) 1445-1449.

[33] E.A. S., B.P. N., Normal- and high-strength fiber reinforced concrete under compression, J. Mater. Civ. Eng., 4(4) (1992) 415-429.

[34] Mansur M. A., Chin M. S., W.T. H., Stress-strain relationship of high-strength fiber concrete in compression., J. Mater. Civ. Eng. 11(1) (1999) 21-29.

[35] Campione G., L. La Mendola, Behavior in compression of lightweight fiber reinforced concrete confined with transverse steel reinforcement, Cem. Concr. Compos. 26(645-656) (2004).

[36] Campione G., Cucchiara C., L.M. L., Steel-concrete bond in lightweight fiber reinforced concrete under monotonic and cyclic actions, Eingineering Structure 27 (2005) 881-890.

[37] M.C. Nataraja, N. Dhang, A.P. Gupta, Stress-strain curves for steel-fiber reinforced concrete under compression, Cement \& Concrete Composites 21 (1999) 383-390.

[38] Z. Guo, Strength an deformation of concrete (Experimental basis and constitutive relation), Tsinghua University press, Beijing, 1997.

[39] L. Li, S. Ruan, L. Zeng, Mechanical properties and constitutive equations of concrete containing a low volume of tire rubber particles, Construction and Building Materials 70 (2014) 291-308.

[40] O.B. M Valle, Behavior of fiber reinforced high-strength concrete under direct shear, ACl Materials Journal 90(2) (1993) 122-133.

[41] C. Jiao, W. Sun, H.Qin, Constitutive equation of SFRHSC under uniaxial compression, Journal of Southeast University (Natural Science Edition) 34(3) (2004) 366-369. 
[42] Ezeldin S, B. N., Normal and high-strength fiber-reinforced concrete under compression, J Mater Civ Eng 4(4) (1993) 415-429. 